\title{
Rational Aggregation
}

\author{
Bruce Chapman
}

Version Post-print/accepted manuscript

Citation Bruce Chapman, "Rational Aggregation" (2002) 1 Politics, Philosophy, (published version) and Economics 337-354.

Publisher's Statement Bruce Chapman, "Rational Aggregation" (2002) 1 Politics, Philosophy, and Economics 337-354.

Copyright (C [2002]. Reprinted by permission of SAGE Publications.

https://doi.org/10.1177/1470594x02001003004

How to cite TSpace items

Always cite the published version, so the author(s) will receive recognition through services that track citation counts, e.g. Scopus. If you need to cite the page number of the author manuscript from TSpace because you cannot access the published version, then cite the TSpace version in addition to the published version using the permanent URI (handle) found on the record page.

This article was made openly accessible by $U$ of $T$ Faculty. Please tell us how this access benefits you. Your story matters. 


\title{
RATIONAL AGGREGATION*
}

Published in 1(3) Politics, Philosophy and Economics (October 2002) 337-54

(Final published version downloadable at http://ppe.sagepub.com/cgi/reprint/1/3/337 )

\author{
Bruce Chapman \\ Faculty of Law, University of Toronto \\ 78 Queen's Park, Toronto, Canada M5S 2C5 \\ bruce.chapman@utoronto.ca
}

In two recent papers ${ }^{1}$ Christian List and Philip Pettit have argued that there is a problem in the aggregation of reasoned judgements that is akin to the aggregation of preference problem in social choice theory. Indeed, List and Pettit prove a new general impossibility theorem for the aggregation of judgements, and provide a propositional interpretation of the social choice problem that suggests it is a special case of their impossibility result. ${ }^{2}$ Specifically, they show that no judgement aggregation function for a group is possible if the group seeks to satisfy certain "minimal conditions" designed to ensure that the function is both responsive to the individually rational views of its members and collectively rational in the set of judgements it holds.

In this article I resist the List and Pettit claim that there is the same propensity for collective irrationality or incoherence in the aggregation of reasoned judgements as there

\footnotetext{
* This paper was presented at the Oxford-Toronto Jurisprudence Symposium in Oxford, February 2001; the Social and Political Philosophy Seminar at the Chaire Hoover d'Ethique Economique et Sociale, Catholic University of Louvain, June 2001; at the School of Law, Universidad Torcuato di Tella, Buenos Aires, October 2001; and at the Annual Meetings of the European Public Choice Society, Belgirate (Lago Maggiore), Italy, April 2002. I am grateful to the various participants at these sessions, and more particularly to John Gardner, Christian List, Philip Pettit, Pierre Salmon, Horacio Spector, and two anonymous referees for their very helpful comments. Financial support from the Social Science and Humanities Research Council of Canada and from the Connaught Fund at the University of Toronto is also gratefully acknowledged.

${ }^{1}$ List and Pettit (2002a), (2002b).

${ }^{2}$ List and Pettit (2002b) are careful to point out that, strictly speaking, their impossibility result does not completely overlap Arrow's result. The conditions that they prove to be inconsistent are somewhat different from Arrow's, even if one puts Arrow's preference rankings in their judgmental form. What they do offer is an impossibility result that comprehends the majority voting paradox, that is, the same paradox that is so often used to exemplify Arrow's more general social choice problem.
} 
is in the aggregation of preference. I argue that reason, because it has a logical structure that is lacking in mere preference, has the effect of giving priority to some aggregations over others, a priority that is not permitted by one of the conditions imposed by List and Pettit. This avoids the incoherence that would otherwise exist if these different aggregations, not consistent with one another, were to compete at the same level of priority. The priority of some aggregations is particularly apparent, I shall argue, if one views the aggregation of judgements through the lens of common law decision-making.

\section{A. The Impossibility Result for the Aggregation of Judgements}

Kenneth Arrow’s famous impossibility result in social choice theory shows that there exists no procedure for the aggregation of rational individual preferences that satisfies certain minimally acceptable conditions and that generates a set of equally rational collective preferences, namely, preferences that are reflexive, transitive, and

complete. ${ }^{3}$ List and Pettit have shown that a similar impossibility result holds for the aggregation of a set of reasoned individual judgements. The formal proof of their result is not in dispute here. My concern is with the real significance of this result for the aggregation of reason.

The working materials for the aggregation of reason are the judgements that a group of individuals might make on a set of logically connected propositions rather than a set of preferences they might have over alternatives that are available for choice, the stuff of more conventional social choice theory. Of course, since it is an aggregation of judgments rather than preferences that is at issue, the rationality constraints will also 
naturally be somewhat different. A set of judgements $J$ is rational, say List and Pettit, if it satisfies completeness, consistency, and deductive closure. Completeness requires that, for any (either atomic or compound) proposition $p$, either the judgement $p$ (“p is true") or the judgement not-p (“p is false”) is in the set of judgements $J$. Consistency requires that, for any proposition $p, J$ must not contain both judgements $p$ and not-p. Finally, $J$ is deductively closed if, whenever the set of judgements $J$ logically entails some further judgement on some proposition, then that judgement is also contained in $\mathrm{J}^{4}$

Of course, each individual may have a set of personal judgements that is complete, consistent and deductively closed, but the question for the aggregation of reason is whether there is any acceptable procedure that will allow a group of such individuals to derive a collective set of judgements that satisfies the same rationality constraints. List and Pettit suggest that the aggregation procedure should somehow be responsive to the judgements that the individual group members make about the different propositions, and in doing so should seek to treat each of the members in an even-handed way. The latter two concerns, together with the further idea that the aggregation procedure should not be artificially limited in its scope, are what motivate List and Pettit

\footnotetext{
${ }^{3}$ Arrow (1963).

${ }^{4}$ Brennan (2001) offers an argument for being sceptical that deductive closure should necessarily be a property of even individual rationality. For suppose that belief in, or assent to, a proposition $s$ is represented by a degree of confidence in the truth of $s$ which is greater than some threshold $\pi^{*}$, where $\pi$ is thought of as the probability that $s$ is true. Then it might be perfectly rational to believe $s$ and to believe $t$ (each in isolation) on such a basis, but not to believe in their conjunction ( $s \& t$ ) even though the conjunction represents the deductive closure on what the individual otherwise believes. Such would be the case if the compound probability of the conjunction fell below $\pi^{*}$. Brennan thinks that this argument supports our giving more credence to our judgements over outcomes than our judgements over the underlying reasons supporting those outcomes. However, I consider a similar sort of situation below, at $\mathrm{n}$. 20, and there my argument is that we should insist that the individual organize her probability assessments under the relevant reasons, and not allow the individual to make a credible claim simply because she can point in some unreasoned way (even probabilistically) to an outcome supported by the possibility of some reason. The difference in our views goes to the sort of claim that is being made, and the precise nature of the burden of rationality that it must carry. Some claims, even if they are right, or right more probably than not, may not
} 
to identify three "minimal conditions” that any such aggregation procedure should satisfy. The three conditions are "minimal" in the usual social choice theoretic sense, namely, that whatever additional requirements one might want to require of a rational aggregation procedure, at least these conditions would have to be satisfied if the procedure is going to be acceptable. Obviously, if these conditions are already selfcontradictory for a rational procedure, then adding further conditions will not be helpful.

The three minimal conditions that List and Pettit specify are:

(1) Universal Domain: A judgement aggregation procedure should accept as admissible any logically possible profile of individual judgement sets so long as these individual judgment sets are themselves rational, i.e., complete, consistent, and deductively closed. The idea here is to be open to a broad range of possible inputs; an aggregation procedure would hardly be viewed as satisfactory if its success depended upon artificially restricting the sorts of individual judgments it had to reconcile.

(2) Anonymity: The collective set of judgements that is derived by the aggregation procedure should be invariant with respect to any permutation of the individual judgement sets across any of the individuals. In other words, no individual's judgement should count for more than that of someone else simply because of who that particular individual is (rather than, say, how good her judgment is).

(3) Systematicity: The collective judgement on any given proposition should depend only on the individual judgements on that proposition (and not, say, on individual judgements on other propositions) and, further, there should be the same sort of 
dependence holding between the collective judgement and the individual judgements for every proposition. ${ }^{5}$

Thus, if two propositions have the same support from the same people, then systematicity requires that they generate the same group judgement. When this idea is combined with the anonymity condition, it effectively becomes a requirement that if two propositions have the same degree of support, though perhaps not from exactly the same individuals, then the group judgement on the two propositions should be the same. This idea does a great deal of work in the proof of the impossibility result, something that one can easily sense in the following example borrowed from the law.

\section{B. The Contract Paradox}

The general problem of aggregating reason to which List and Pettit refer can be given a more particular legal interpretation by way of the following example. ${ }^{6}$ Suppose that a panel of three judges must decide, by majority vote, whether a defendant should pay damages to a plaintiff for breach of contract. After hearing all the arguments, Judge $A$ believes that there is a contract, but that the defendant has not breached it in this case. Thus, he is inclined to find for the defendant. Judge $B$, on the other hand, believes that the conduct in question does amount to a breach, but that the contract here has not been properly formed. Thus, she too would find in favour of the defendant, albeit for a reason different from that offered by Judge $A$. Finally, Judge $C$ finds both that there is a contract

\footnotetext{
${ }^{5}$ The first part of this requirement closely resembles Arrow's condition of "the independence of irrelevant alternatives", and the second part adds something very close to Kenneth May's condition of "neutrality". See Arrow (1963) and May (1952). May also refers to an anonymity condition that, in the social choice context, is fully analogous to the one required by List and Pettit for judgement aggregation functions. ${ }^{6}$ Kornhauser (1992) seems to have been the first to fully analyse this sort of problem in a legal context and coined the term "doctrinal paradox" for it. However, the phenomenon, without a name and for only a very
} 
and that it has been breached. Judge $C$, therefore, would favour the plaintiff's claim.

Thus, a majority of the judges, $A$ and $B$, share the view that the defendant should win in this case and, absent an obligation to provide common reasons, would effectively choose that as their preferred result. The views of the different judges are represented in summary form in Table 1 below.

\begin{tabular}{|c|c|c|c|}
\hline & $\begin{array}{c}\text { (1) } \\
\text { There was a } \\
\text { contract. }\end{array}$ & $\begin{array}{c}\text { (2) } \\
\text { There was conduct } \\
\text { constituting breach of } \\
\text { such a contract. }\end{array}$ & $\begin{array}{c}\text { (3) } \\
\text { There was a breach } \\
\text { of contract. }\end{array}$ \\
\hline Judge $\boldsymbol{A}$ & True & False & (P\&Q) \\
\hline Judge $B$ & False & True & False \\
\hline Judge $C$ & True & True & True \\
\hline Majority & True & True & False \\
\hline
\end{tabular}

\section{Table 1}

One can easily appreciate that this example is illustrative of the general impossibility result proved by List and Pettit. ${ }^{7}$ The universal domain condition implies that Table 1 is an admissible problem for the aggregation of reason: every individual's personal set of judgements across the three columns is rational in the way required, e.g., for each individual, ( $P \& Q$ ) if and only if $P$ and $Q$. Completeness requires that the judgment aggregation function (here it happens to be majority rule) conclude either True or False in the last row for each of the three propositions in the three columns. Suppose it

brief discussion, also appeared for discussion in Kornhauser and Sager (1986). The doctrinal paradox was first introduced into a social choice framework in Chapman (1998).

${ }^{7}$ It is essentially this example that List and Pettit (2002a) use to introduce their discussion of the general impossibility. 
concludes True for the column (1) proposition $P$ (as illustrated above under the requirements of majority rule). Then the anonymity and systematicity conditions combine (in the way alluded to earlier) to imply that it must also conclude True for the column (2) proposition $Q$ and, analogously, False for the column (3) proposition ( $P \& Q)$, since the degree of support (here it is equal majority support) for each of these three judgements is the same. But this violates deductive closure, since True judgements on each of the atomic propositions $P$ and $Q$ should imply a True judgement on the compound proposition (P\&Q). A similar difficulty arises if the judgement aggregation function concludes False for proposition $P$ (in which case under systematicity and anonymity it would have to conclude False for proposition $Q$ and True for the compound proposition (P\&Q), another contradiction of collective rationality). Thus, we have an instance of the general impossibility result.

As List and Pettit suggest, and as the example shows so clearly in tabular form, the source of the impossibility is in the tension that can sometimes exist "between two plausible demands that we might want to make on the aggregation of judgement." ${ }^{8}$ The first demand is the one that requires the group to be responsive (somehow) to the views of its individual members. This surely makes sense. Individual judgements, after all, are the only judgements with which the group can begin and, as we shall see in the next section, there is a sound epistemic basis for relying on simple majority rule as the method for aggregating these individual judgements into a collective judgement. It is worth noting, however, that under systematicity List and Pettit effectively elevate this demand to a requirement that the group be equally responsive to the members' views on each

\footnotetext{
${ }^{8}$ List and Pettit (2002a), at p. .
} 
proposition. Whether the stronger requirement of equal responsiveness continues to make sense remains to be seen.

The second demand is the one that requires the group to reach a collective set of judgements that is rational. Again, this demand seems plausible, at least for anyone who wants to take seriously the possibility of a rational aggregation of judgements. However, as the table shows, the first demand for equal responsiveness down each of the columns can generate a collective set of judgements that is irrational as we move across the last row.

In the next section I will argue that systematicity is a problematic condition to impose on the aggregation of reason. By requiring it, List and Pettit effectively remove the discipline of reason from social choice and, with predictable results, reduce the aggregation of reason to the aggregation of mere preference with all its attendant problems. Indeed, somewhat ironically, this is what their propositional interpretation of the majority voting paradox suggests. In the voting paradox, reason has no role to play, much less a public, or aggregate, reason. The real lesson of their impossibility result, I would suggest, is not that the aggregation of reason is as much subject to collective irrationality as the aggregation of preference. Rather, the implication is the reverse: their result suggests that what the aggregation of preference might need, if it is to avoid collective irrationality, is the extra discipline, or conceptual structure, that a truly public reason provides. ${ }^{9}$ However, this additional structure is precisely what is neutralized by the systematicity requirement.

To illustrate these points I shall make further use of examples borrowed from common law decision-making. The common law courts, after all, idealize the aggregation 
of reason. Judges are obliged, first, to offer publicly comprehensible reasons in support of a decision for a given case and, second, to integrate the results of different cases into a coherent body of law. In the next section we will look more closely at each of these moments of rational aggregation in law and see that, in tandem, they suggest a particular and sensible way to relax the systematicity requirement imposed by List and Pettit.

\section{A Critique of Systematicity: The Obligations of Public Reason}

\section{Public reasons in support of a decision}

The common law is more than a mere collection of authoritative resolutions for disputes. Indeed, if there is one thing that effectively distinguishes the common law as a method of collective decision-making, it is the obligation that the judges have to offer publicly comprehensible reasons supporting their decision. Unlike forms of market or political decision-making, for example, where individual rights holders or legislators can make authoritative decisions without good reason, in law the reasons that are publicly articulated in support of some decision form a large part of the authoritative basis for it. ${ }^{10}$ Weak reasoning will typically undermine the authority of a case and leave it exposed to the indignity of being distinguished into oblivion, if not completely overturned or reversed.

One might reasonably ask why the common law courts insist on offering publicly articulated reasons in support of their decisions. Of course, one answer is that the reasons

\footnotetext{
${ }^{9} \mathrm{I}$ have developed this argument in some detail in Chapman (1998).

${ }^{10}$ I do not mean to suggest that the passage of legislation is never informed by reasoned debate. Indeed, for the 'republican' theory of politics, this sort of deliberative exchange is often thought to be central and important for grounding the authority of political decision-making in general. I only mean to argue that the authority of any given legislative act is, ultimately, a matter of its proper positing by some legitimate lawmaker (e.g., a majority of the legislators). It is not affected by the possibility that, after reasoned debate, the particular reasons that prevailed were not especially good.
} 
offer guidance to other litigants and judges on how similar cases should be decided, either elsewhere or in the future. And, even for the parties involved in the immediate dispute, there is some process value, beyond simply having their case decided, in having the judges explain to them what has happened and why.

These are familiar enough arguments favoring the common law practice of publicly articulating the reasons that support a given result. However, there is another argument favoring the practice that is less often noticed and which relates to the paradoxical results that are being analyzed here. To see it, one first has to take seriously the idea that judges are not so much indicating their own preference for a result as offering their opinions on what the law requires in a given case. This is a question of expertise, or of views that could be either right or wrong, or true or false. With this idea in place, it is easier to understand, with some help from the Condorcet jury theorem, why it is that a court might want (i) to decide a case by majority rule, and (ii) to offer a set of reasons supporting its decision. Support for (i) comes from a straightforward application of the theorem, but the additional need for (ii) can be seen once one appreciates the ambiguities that are present for the application of that theorem in the context of something like the contract paradox discussed above. Let us consider each of these points in turn.

Condorcet showed that if one can assume that any one voter is more likely to be right than wrong about any given proposition, and supposing that all voters had the same such (independent) likelihood of being right, then a majority of such voters is more likely to be right in its majority view than is any one of the voters alone. ${ }^{11}$ The general argument is easy enough to illustrate. Suppose, for example, that, for any given 
proposition, each of the three judges in Table 1 has an independent 2/3 chance of being right. Then the court, using majority rule, will be right when at least two of the judges (i.e., a majority) are right. The chance of this happening is the sum of the chances of either $A$ and $B$ (but not $C$ ) being right (or a chance of $2 / 3 \times 2 / 3 \times 1 / 3=4 / 27$ ), or $B$ and $C$ (but not $A$ ) being right (again, a 4/27 chance), or $A$ and $C$ (but not $B$ ) being right (also a $4 / 27$ chance), or $A, B$, and $C$ all being right (or a chance of $2 / 3 \times 2 / 3 \times 2 / 3=8 / 27$ ). The sum of this disjunction of four probabilities, which represents all the possible ways in which a majority of the judges might get the proposition right, is $20 / 27$, which is higher than the $2 / 3$ (or 18/27) chance that any one of the judges is right. This higher probability of the group being right can take us some way towards justifying the use of majority rule for the aggregation of individual judgements.

However, it is important to appreciate that, for the use of majority rule to receive this epistemic support from the Condorcet argument, the different individual decisionmakers who form the majority must be addressing the same proposition (or, at least, not any inconsistent propositions). ${ }^{12}$ This may seem an obvious enough requirement, but the Table 1 contract example suggests the need to be vigilant about it. For, as we come down column (3) in that Table, it is apparent that Judge $A$ has voted the compound proposition ( $P \& Q$ ) false because he thinks the atomic proposition $Q$ is false. We might say, more

\footnotetext{
${ }^{11}$ Condorcet (1976). I borrow the illustration that follows this footnote in the text from Pettit (2001).

${ }^{12}$ If two members of a majority are judging, or voting on, two inconsistent propositions $x$ and not- $x$, then, contrary to what the jury theorem requires, it cannot be that each member of the majority is more likely to be right than wrong in the judgements he or she makes since that would imply that the sum of the probabilities of $x$ and not- $x$ being true is greater than 1. (Note, however, that two individuals can judge the same proposition differently, or inconsistently, even if each is more likely to be right than wrong on that proposition; that possibility is allowed because each is only probably, and not certainly, right.) The same difficulty would plague those versions of the jury theorem that require only that the average of the probabilities that each member of the group of voters is right be greater than .5; see Grofman, Owen and Feld (1983), Theorem 5. The average for the group cannot be greater than .5 for both the $x$ and not- $x$ propositions. At most the average would have to be .5 , in which case majority voting adds nothing to the credibility of individual voting.
} 
fully and accurately, that Judge $A$ has voted for the proposition "Not- $(P \& Q)$ because not$Q$ ” in column (3) (or, even more accurately, "Not- $(P \& Q)$ because, although $P$, not- $Q$ ”). But Judge $B$ has voted the compound proposition false in column (3) because she believes the atomic proposition $P$ is false. Again, in column (3), a more complete and accurate articulation of the proposition Judge $B$ is voting for is "Not- $(P \& Q)$ because not$P$ ” (or, even more accurately again, “Not- $(P \& Q)$ because, although $Q$, not- $P$ ”). But this means that the two judges who form the majority in column (3) of Table 1 are not actually voting on the same proposition at all. Indeed, as the most accurate and detailed articulations of the propositions reveal, the two different propositions are not even consistent with one another. Thus, their majority vote for false in column (3) does not receive the same epistemic support from Condorcet's theorem that is received by the analogous majority votes for true on each of the atomic propositions $P$ and $Q$ in columns (1) and (2). ${ }^{13}$

Now, if the Judges $A$ and $B$ had to offer reasons for the judicial outcome ("not$(P \& Q)$ ) that they appear to jointly favor in column (3), this difference between them would likely become apparent. Certainly, it would be a challenge for this majority, despite their shared preference for an outcome favoring the defendant, to articulate any common or coherent legal view supporting that result. There are two legal issues underlying this case, the breach issue and the contract formation issue. These are the issues that make the case rationally comprehensible to the judges, a proper object of their legal understanding. Yet, on each of these salient legal issues in the case, the two judges

\footnotetext{
${ }^{13}$ Of course, it is possible that these two "atomic" propositions might themselves be compounds of further "sub-atomic" propositions, thus generating another iteration of the judgement aggregation paradox at this lower level. Some might argue that this attests to a general indeterminacy in the structure that makes the paradox possible, something that renders it less important. Others might argue that this only goes to show
} 
who form the majority in favor of the defendant have diametrically opposed views. Thus, on the only issues that they can sensibly speak in this case, the two judges have nothing in common to say. As a group they are rendered logically speechless.

The majority's inability to articulate any logical support for what it wants to do is also likely to mean that it will be awkward for the majority to do what it wants given what it must say. But, far from being a problem, this is precisely why it might be useful to require a majority of judges to offer publicly comprehensible reasons in support of their view. For an obligation of public reason exposes the members of the majority to the thought that they might not be addressing the same proposition and, more importantly, to the idea that the plurality of propositions that they are voting for may not be consistent. But this only suggests that the Condorcet jury theorem may not provide their majority judgement with any epistemic support and, therefore, that it might not be a judgement worthy of being acted upon after all.

By contrast, in the way that the systematicity and anonymity requirements are used by List and Pettit, there is just as much judicial authority in the aggregation down column (3) as there is in the aggregations down columns (1) and (2). After all, the level of majority support against the column (3) proposition appears to be the same as the level of majority support in favor of the propositions in columns (1) and (2). In other words, for List and Pettit, the authority that is present in any given aggregation of judgements just is a function of how the different votes come out as a quantitative matter. ${ }^{14}$ In this way, systematicity (combined with anonymity) effectively requires that the judgement

that the paradox occurs with greater frequency than one first realizes, something that might magnify its significance. For debate around this question, see Rogers (1996) and Post and Salop (1996).

${ }^{14}$ This point is explicitly acknowledged in List and Pettit (2002b) section 7. List and Pettit also show that the consequence for the judgement aggregation function of this strictly quantitative focus is that it cannot 
aggregation function ignore the fact that the proposition in column (3) is, for each judge, a reasoned consequence of the propositions in columns (1) and (2), and that the majority of judges in column (3) may have used different reasons to come to their conclusion. It is as if the judges had accessed the compound proposition in column (3) directly, or in a way not mediated by the reasons arising out of their judgements on the atomic propositions (1) and (2). For if the process was sensitive to the reasoned basis for the conclusion of each of the judges in column (3), then there would be a greater awareness that different (and possibly inconsistent) propositions might actually have been voted on there.

Systematicity, therefore, is a condition that effectively asks the judgement aggregation function to treat the individual judgements in column (3) as if they are as immediately accessible and unreasoned as the judgements are over the atomic propositions in columns (1) and (2). But this effectively neutralizes the structure of reason and reduces it to something more like a basic (or brute) predisposition or preference. Perhaps we should not be too surprised, therefore, that a judgement aggregation function incorporating the systematicity condition would encounter an impossibility result akin to those seen elsewhere in social choice theory where the rational aggregation of preferences is at issue.

Certainly this is what is suggested by the propositional interpretation of the majority voting paradox which List and Pettit offer to show the close relation that exists between their impossibility result and Arrow's. ${ }^{15}$ In that interpretation the different

effectively distinguish rational from irrational voting inputs. As argued here, that is because the systematicity condition forces an abstraction from the discipline of reason altogether.

${ }^{15}$ Of the two papers, List and Pettit (2002b) offers the most explicit comparison of the two impossibility results. 
individual preference rankings are replaced by different individual judgements that the various voters can make on social ranking propositions. For example, in the propositional interpretation, an individual's preference for alternative $x$ over alternative $y$ is replaced by the individual's judgement that the proposition " $x$ is socially preferred to $y$ ” is true. Not surprisingly, given the familiar majority voting paradox, three different majorities can offer up a set of judgements on these ranking propositions that is not collectively rational. But here, precisely because preferences are at issue, whatever their propositional garb, each of the propositions is immediately accessible for each voter, and an aggregation down any one of the columns must have the same priority as any other. In other words, in the context of preference aggregation, systematicity does seem to apply, but that is only because reason does not.

Now List and Pettit argue that reason does impose a structure on preference, viz., that preferences should be transitive. ${ }^{16}$ Thus, under the propositional interpretation, it will be said that if the two propositions " $x$ is socially preferred to $y$ " and " $y$ is socially preferred to $z$ " are true, then we can deduce that the third proposition " $x$ is socially preferred to $z$ " is true. Thus, they argue that there is same sort of deductive closure requirement in their propositional interpretation of the majority voting paradox as there is in the judgement aggregation paradox in Table 1. Thus, the argument goes, if systematicity is a sensible requirement in the one, it is a sensible requirement in the other.

But that is to misunderstand the transitivity requirement, for it suggests that the preference over the pair of alternatives $(x, z)$ is somehow derived from the preferences over the other pairs of alternatives $(x, y)$ and $(y, z)$ in the same way that the truth of a compound proposition $(P \& Q)$ is derived from the truth of the two atomic propositions $P$ 
and $Q$ that constitute it. However, the preference judgement over the pair $(x, z)$ is just as basic, or just as immediately accessible, as the preference judgement over the other two pairs of alternatives. Thus, the transitivity requirement is better understood as a negative requirement on a conjunction, viz., that it not be the case that " $x$ is socially preferred to $y$ ", that " $y$ is socially preferred to $z$ ", and that " $x$ is not socially preferred to $z$ " ${ }^{17}$ From this conjunctive requirement, no specific conclusion can be derived as to what preference there should be for any particular pair of alternatives. Any one of the three propositions could be revised to achieve overall coherence. In this respect the conjunctive version of the transitivity requirement, and not the deductive version, is in keeping with the equally basic status of each preference. As suggested above, this equally basic status of each preference also supports the idea that, in such a context, systematicity might be a reasonable condition to impose on an aggregation procedure.

However, now List and Pettit will argue that the requirement of deductive closure should be read the same way in Table 1, viz., in a way that, for example, allows an individual, first, to directly access the compound proposition $(P \& Q)$ as false and, second, to relax, as logic requires, either one or the other (or both) of the two atomic propositions $P$ and $Q$. This is, of course, to relax systematicity, but not in the way I have proposed above. Obviously, if the majority of judges in column (3) of Table 1 could access the column (3) compound proposition immediately, and not by reason of the atomic propositions (1) and (2), then there would not be the same scope for the worry that they were not addressing the same proposition in their vote and, therefore, there would be less reason to question the epistemic support that their vote might have from the Condorcet

\footnotetext{
${ }^{16}$ List and Pettit (2002b), section 4 Table 2.

${ }^{17}$ Nozick (1993), at 159, makes this same point.
} 
theorem. However, in section C.2 of the paper, I offer some arguments for resisting this method for achieving collective rationality. To see the difficulties, it will again prove useful to see how the common law construes the notion of public reason, only this time across different cases rather than within a single case.

\section{Public reason across different cases}

To be fair, List and Pettit do consider the possibility of relaxing systematicity as a way to avoid incoherence in the aggregation of group judgements. However, the problem, they suggest, is deciding which of the different group judgements is to be given priority. Without an argument focused on this particular issue, there is merely the symmetry of the different group judgements, each supported to the same degree by individuals in the group, and no reason to give any of these judgements a greater or lesser priority. This symmetry is precisely what is captured by systematicity.

The earlier arguments appear to provide some reason, at least in the context of majority rule and the Condorcet jury theorem, for giving majoritarian judgements over compound propositions a lesser priority than the majoritarian judgements over the corresponding atomic propositions that make up the compound proposition. After all, behind the apparent agreement over the compound proposition, there may be, at the atomic level, a plurality of inconsistent propositions in play, something that we might only become aware of if the majority is obliged to offer reasons for its view.

But List and Pettit would likely reject this earlier argument as offering too simple an understanding of the relationship that must exist between between reasons, or premises, and a conclusion. Consider the following remarks from List and Pettit (2001a): 
What determines whether someone will see a proper subset of the propositions on which they and their group have to judge as fit to be treated as premises? People often differ in the background assumptions they make as to which sorts of propositions matter most, and for this reason they will often differ in which propositions, if any, they see as fit for treatment as premises. For one person certain atomic propositions [like $P$ and $Q$ ] may seem most natural to be treated as premises in relation to a compound proposition, [say $(P \& Q)$ ], on which they also have to judge. For another it may seem that the compound proposition lends itself more readily to resolution than any of the atomic propositions, so that assent to the atomic propositions ought to be shaped by whether the compound proposition commands assent, not the other way around. One individual's conclusion may be another's premise; one individual's modus ponens may be another's modus tollens. $^{18}$

With these remarks, List and Pettit effectively challenge the idea, which I have developed above, that the compound proposition must be reached by way of the atomic propositions as prior premises. Call this the modus ponens approach. Instead, they suggest that the compound proposition could itself be immediately accessed as the proposition lending itself “more readily to resolution". Then reason, in the form of modus tollens, would take

\footnotetext{
${ }^{18}$ List and Pettit (2002a), at p. .
} 
the voters to a reshaping of what their views should be on the various atomic propositions. $^{19}$

While List and Pettit mean to address two equally plausible ways in which systematicity might be relaxed, the effect of their remarks is to question the priority that one is tempted to give to the aggregations over atomic propositions as reasons for accepting the compound proposition. But without a sense of priority one way or the other, we are inching back to the very symmetry that the systematicity condition requires. In this section I shall argue that systematicity should be relaxed and, more particularly, that it should be relaxed so as to give the aggregations over the atomic propositions priority over the aggregation over the compound proposition. However, to make this point, I cannot now use the Condorcet jury theorem argument, as this now appears to beg the question against List and Pettit that the majority of judges voting against the compound proposition were voting on the basis of reasons rather than in some more immediate way. However, I shall now show that there are some special problems involved in accessing the compound proposition directly, and then using reason (or modus tollens) to shape one's views on the atomic premises.

These problems are again best seen in the light of a common law example that is illustrative of the judgement aggregation paradox. However, it is helpful at this point to introduce a slight variation on the paradox. In Table 1, the paradox appeared in conjunctive form. That is, the paradox was to be found in the fact that a majority of the court voted for each of the atomic propositions $P$ and $Q$ as true, but rejected the conjunction of those propositions $(P \& Q)$ as false. However, one can easily imagine that

\footnotetext{
${ }^{19}$ Of course, the distinction is not really between reasoning based on modus ponens and reasoning based on modus tollens. These are logically equivalent. Rather, the distinction is between beginning with the atomic
} 
the paradox might arise for a disjunctive compound of the atomic propositions.

Specifically, it might be that a majority of the court would reject both atomic propositions $P$ and $Q$ as false, and yet accept the compound disjunction ( $P$ or $Q)$ as true. Suppose, for example, that our same panel of three judges had to decide whether a given tribunal had jurisdiction to hear some legal dispute. There are two (and, let us say, only two) possible ways for the tribunal to take jurisdiction, $J 1$ or $J 2$, each of which, if available on the facts, is entirely sufficient to settle the jurisdictional dispute. Thus, there will be jurisdiction $J$ if and only if ( $\mathrm{J} 1$ or J2), that is, if the compound proposition is satisfied in its disjunctive form. Now suppose that Judge $A$ believes that this tribunal can take jurisdiction $J$ on the basis of $J 1$, but not $J 2$. Judge $B$ believes that the proper way for the tribunal to take jurisdiction $J$ is by way of $J 2$, but not $J 1$. Finally, Judge $C$ believes that jurisdiction $J$ is not available for this tribunal under either $J 1$ or $J 2$. Table 2 sets out the views of the different individual judges, together with the views of the majority, on each of the three propositions that are in dispute in this case.

\begin{tabular}{|c|c|c|c|}
\hline & $(1)$ & $(2)$ & (3) \\
& There is $J 1$. & There is $J 2$. & There is $J$ (i.e., $(J 1$ or $J$ 2)). \\
\hline Judge $A$ & True & $Q$ & (P or $Q$ ) \\
\hline Judge $B$ & False & False & True \\
\hline Judge $C$ & False & True & True \\
\hline Majority & False & False & False \\
\hline
\end{tabular}

Table 2

propositions and beginning with the compound proposition. 
Again, we have what is now a familiar problem. While Judges $A$ and $B$ form a majority in favor of finding jurisdiction $J$ in column (3), they find this for conflicting reasons. Moreover, the problem, again, is not that there is no majority view on these reasons. Rather, the court does have a majority view and, as one can see from the last row in columns (1) and (2), it is that neither $J 1$ nor $J 2$ are adequate reasons for this tribunal to take jurisdiction. Thus, if forced to articulate publicly their views on each of the possible routes to jurisdiction, Judges $A$ and $B$ would have nothing in common to say. ${ }^{20}$

However, the real benefit of presenting the judgement aggregation paradox in this disjunctive form is that it makes it easier to separate out the three columns into three different decisions since each column has a kind of sufficiency on its own. This will allow us to test the plausibility of relaxing systematicity by giving the aggregation down column (3) some kind of independently accessible priority (by way of modus tollens) over the aggregations down columns (1) and (2). As we shall now see, however, if a court follows the modus tollens strategy, then the court's decision in any particular case will vary with the order in which the cases arise, that is, the decisions will be path dependent. Moreover, the decision that the court will come to on one of the atomic propositions, $J 1$

\footnotetext{
${ }^{20}$ Here is another example of the disjunctive version of the paradox that should really set a lawyer's teeth on edge. (The example is adapted from one used by Levmore (2001) to make a different point about the conjunction of independent probabilities.) Suppose that a plaintiff was injured while using some product and that she advanced two separate and independent claims for the recovery of damages from the defendant manufacturer. The plaintiff might argue that the product was either defectively manufactured or sold with an inadequate warning, where either one of these two arguments, call them $J 1$ and $J 2$ to match the columns in Table 2, would be sufficient, if successful, to win a judgement $J$ for damages. Now suppose that a majority of the court rejects each of the plaintiff's arguments $J 1$ and $J 2$ in the same way that Table 2 suggests. Would it nevertheless be possible for the plaintiff to argue that she should win the judgement $J$ in column 3 ? After all, a majority of the judges, $A$ and $B$, do think that the plaintiff should win $J$, albeit for different reasons. A lawyer is tempted to reply that the plaintiff's position is inadequate because in law she has an obligation to frame her claim against the defendant as an argument, that is, under some sort of conceptual structure. It will not do for the plaintiff to show only that the defendant owes (or, even, probably owes) her damages for some reason. Instead, she must show (more probably than not) that there is $a$ reason (that is, at least one particular reason, woven out of some particular account of transactional wrong) for the claim. It is in this respect that some claims, even if they are right (or right more probably than not), may not
} 
or $J 2$, will depend somewhat arbitrarily, and irrationally, on the identity of the particular judges who have particular views across the cases.

Consider a court that was confronted first with the sole issue of whether $J 1$ is a possible way for the tribunal to take jurisdiction. Then, having decided that issue negatively on the basis of its best judgement (as represented by column (1)), it might be asked in another case whether there was jurisdiction to be granted according to J2. Again, its best judgement (see column (2)) would provide a negative answer to that question. But now suppose it was confronted with the compound question represented by column (3) or, what amounts to the same thing, Table 2? (If we think that this compound question is unlikely to arise given what the court has already decided on the atomic propositions in columns (1) and (2), then we have already conceded the point at issue.) Could this court rationally now support an affirmative answer on the disjunctive whole given what it has already decided on each of its component parts? The systematicity condition suggests, of course, that it could, but that is only to reiterate that, under that condition, there is the possibility of group irrationality here. To avoid that irrationality the court must violate systematicity and decide the compound case not only in accordance with its prior decisions, but also according to its current reasons and modus ponens.

Now it might be said that this is a sequence of cases that happens to favor the modus ponens approach, but that an alternative sequence, where the compound case represented by column (3) or by Table 2 comes either first or second in the sequence, would cast the modus tollens approach in a better light and make the modus ponens approach seem less necessary. For suppose the court had to decide the compound case 
first, and did so according to its column (3) sense of the appropriate outcome. Thus, it decided that there was $J$ according to the majority view. Then, if confronted with the column (1) case asking more particularly if $J 1$ was a reason for granting jurisdiction (note that this would be an open question since no publicly sensible reasons would be forthcoming as guidance from the previously decided compound case), it would answer in the negative. What then must the court do in the third case, which asks the column (2) question about jurisdiction according to $J 2$ ? To be rational across the different cases (rather than "systematic" down "like" columns in the List and Pettit sense), the court would have to accept that $J 2$ was now an appropriate way for the tribunal to take jurisdiction. This, after all, is what modus tollens demands; if ( $J 1$ or J2), and not-J1, then J2 must follow. But suppose now that the cases came up in a different order. Suppose, for example, that the court had to decide the compound case first and the column (2) case second. Then it would decide in the compound case that, according to the majority, there was (J1 or J2), and in the second case, again according to the majority, that there was not-J2. Already, this last result on $J 2$ differs from what was decided for this case in the earlier sequence. But now there would be a further path dependent result in the third case concerning $J 1$. For if ( $J 1$ or $J 2$ ), and not-J2, then, by modus tollens, $J 1$ must follow, exactly the opposite result which was achieved for $J 1$ in the earlier sequence under modus tollens. Thus, path dependent results would be the rule under modus tollens, whereas under modus ponens, the compound case ( $J 1$ or $J 2$ ), and each of the atomic cases $J 1$ and $J 2$, would all be decided the same way regardless of the order in which the cases might arise. $^{21}$

\footnotetext{
${ }^{21}$ In a recent unpublished paper, List (2002) argues that the modus ponens decision process (as much as the modus tollens decision process) will generate path dependent results. However, his proof turns on allowing
} 
Further, there is some reason to believe that the modus tollens route to achieving overall coherence across these different cases more deeply denies the spirit of what List and Pettit might have been hoping to achieve by way of their systematicity condition in the first place. Recall that the effect of combining the systematicity condition with the anonymity condition was that if any two propositions had the same degree of support, although not perhaps from exactly the same individuals, then the group judgement on the two propositions should be the same. Now, of course, a strict adherence to systematicity over any two propositions is not possible under either the modus ponens or the modus tollens route to coherence; that, again, is simply what the judgement aggregation paradox exemplifies and what the List and Pettit impossibility result proves more generally. However, there is a sense in which the modus ponens or reason-based approach to coherence might allow for something like "systematicity" for a single proposition in a way that the modus tollens approach does not. For suppose in Table 2 that the views of Judge $A$ and Judge $B$ were reversed on the issue of $J 1$, that is, that Judge $A$ agreed with Judge $C$ that there was no proper way to grant jurisdiction in these sorts of cases under either $J 1$ or $J 2$, and that Judge $B$ thought both $J 1$ and $J 2$ were proper ways to grant jurisdiction. Then, while this reversal would not change in any way the degree of support for either the $J 1$ or the $J 2$ cases, but only who gave the support, it would, nevertheless,

the group (1) to follow its (unreasoned) "initial disposition" on each case as it arises, at least in so far as there is no conflict under modus ponens with prior decisions, but (2) use modus ponens to correct these "initial dispositions" in the later cases when there is such conflict. Under such a modus ponens process, there is, of course, path dependence. Indeed, the path dependence is immediately implied by (and, further, implies) a set of aggregate judgements (each considered only as "initial dispositions", or as an aggregation down any one column) which is not deductively closed, and for which any contradictions are resolved in favour of prior decisions. However, in my modus ponens decision process, the group's judgement in the compound case is itself decided by modus ponens, whenever it occurs, and not as an (unreasoned) "initial disposition" for an outcome. This prevents the decision in the compound case from varying in any way with the decision path. 
make for a difference in the result under the modus tollens approach. For now a court considering the cases in the order where the compound case came first, and the J1 case came second, (indeed, any order of the cases would do) would decide the $J 2$ case in the negative, exactly the opposite of the result that we observed for the $J 2$ case earlier under modus tollens. However, it is unclear exactly why this should be thought to be a sensible change in the result for the $J 2$ case, particularly since, at least for the $J 2$ question, neither the degree of support for a negative result in that case, nor the distribution of that support across the judges, has changed in any way. It is in this sense that modus tollens, or the conclusion-centered view, does not respect systematicity, even for a single proposition. Modus ponens, or the reason-based view, on the other hand, delivers the same results in the three cases so long as the degree of support on the underlying reasons remains the same. In this respect, therefore, the latter approach is not only constant in the results it achieves, regardless of the sequence of the cases; it is also not arbitrarily dependent on the identity of which particular judges have which particular views across the cases.

\section{Conclusion}

In this paper I have tried to argue that group decisions based on reasons are mediated by a logical structure that is lacking in group decisions based merely on preference. This additional logical structure means that the level of agreement of individual judgements on some propositions will have a priority over comparable levels of agreement on others. Sometimes this will be because the level agreement of individual

Incidentally, it might appear on first glance that the impossibility theorems in List (2002) do not require "systematicity". However, systematicity is assumed in the idea that the group uses the same 
judgements on some of the propositions is more apparent than real; the detailed differences might only be appreciated if one attends to the different reasons individuals might have for their judgements or if, as law does, we insisted that the individuals articulate reasons in common for their view. At this level of detail we might see that there is no one proposition being agreed upon, or even that the different propositions being addressed are not consistent. This presents problems for why we might want to be responsive to a given level of agreed judgements in the first place, a point that the Condorcet jury theorem makes particularly clear.

At other times the priority that should attach to some agreements of judgement over others will only become apparent if we are concerned to combine the different judgements into a coherent body of decisions where each decision is capable of some sort of rationalization, again the sort of thing to which the common law aspires. I have argued that this concern argues for a priority to be given to levels of agreed judgement over atomic propositions rather than comparable levels of agreement over the compound propositions constituted out of these atomic propositions. Otherwise, there is a danger that the group will have to make a decision that it does not want and that is arbitrarily path dependent, that is, dependent on the sequence in which the different cases arise. Furthermore, to attach priority to the wrong aggregation of judgements may mean that a group decision on a given proposition will be dependent, somewhat arbitrarily, on the identity of what particular decision-makers have what particular views as we move from one proposition to another rather than, more substantively, on what their views are on that given proposition. This arbitrary variation in the judgement provided on a given proposition deeply violates the value that List and Pettit might well have meant to capture 
in their systematicity condition. Their mistake, I have argued, was to impose the requirement of systematicity across judgements on different propositions. 


\section{References}

Arrow, K. J. (1963) Social Choice and Individual Values, Second Edition (New Haven, CT: Yale University Press )

Brennan, G. (2001) “Collective Coherence?” 21 International Review of Law and Economics 197

Chapman, B. (1998) “More Easily Done Than Said: Rules, Reasons, and Rational Social Choice” 18 Oxford Journal of Legal Studies 293

Condorcet, Marquis de (1976), Condorcet: Selected Writings (Indianapolis: BobbsMerrill)

Grofman, B., Owen, G., and Feld, S., (1983) “Thirteen Theorems in Search of the Truth” 15 Theory and Decision 261

Kornhauser, L. (1992) “Modelling Collegial Courts II: Legal Doctrine” 8 Journal of Law, Economics and Organization 441

Kornhauser, L. and Sager, L. (1986) “Unpacking the Court” 96 Yale Law Journal 82

Levmore, S. (2001) “Conjunction and Aggregation” 99 Michigan Law Review 723

List, C. (2002) “Discursive Path-Dependencies” (unpublished).

List, C. and Pettit, P. (2002a) “Aggregating Sets of Judgements: An Impossibility

Result”, forthcoming 18 Economics and Philosophy

(2002b) “Aggregating Sets of Judgements: Two Impossibility Results Compared”, forthcoming Synthese

May, K. (1952) “A Set of Independent, Necessary and Sufficient Conditions for Simple Majority Decision” 20 Econometrica 680

Nozick, R. (1993) The Nature of Rationality (Princeton: Princeton University Press) 
Pettit, P. (2001) “Deliberative Democracy and the Discursive Dilemma” 11 Philosophical Issues (Supp. Nous)

Post, D. and Salop, S.(1996) “Issues and Outcomes, Guidance, and Indeterminacy: A Reply to Professor John Rogers and Others” 49 Vanderbilt Law Review 1069

Rogers, J. (1996) “Issue Voting by Multimember Appellate Courts: A Response to Some Radical Proposals” 49 Vanderbilt Law Review 993 